\title{
Pengolahan Data Kolom Air dari Multibeam Echosounder untuk Mendeteksi Gelembung Emisi Gas Dasar Laut
}

\author{
Anwar Ghazali, dan Danar G. Pratomo \\ Departemen Teknik Geomatika, Fakultas Teknik Sipil dan Perencanaan, Institut Teknologi Sepuluh \\ Nopember (ITS) \\ e-mail: anwar.ghazali13@mhs.geodesy.its.ac.id, guruh@geodesy.its.ac.id
}

\begin{abstract}
Abstrak-Selama ini survei hidrografi menggunakan multibeam echosounder selalu terfokus pada pengambilan data kedalaman dasar laut atau data batimetri. Selain data batimetri, multibeam echosounder dapat mengakuisisi jenis data lain yang selanjutnya dapat dianalisis dan diteliti lebih dalam lagi, salah satu contohnya adalah data kolom air. Data kolom air mampu memvisualisasikan obyek yang ada pada kolom air yang sebelumnya tidak dapat terlihat jika hanya menggunakan data batimetri saja. Dengan menggunakan data kolom air, kita dapat melakukan pemetaan kolom air untuk mengamati obyek yang terletak diantara permukaan perairan dan dasar perairan. Pada penelitian ini, data batimetri dan data kolom air yang berasal dari multibeam echsounder akan digabungkan untuk mencari dan menganalisis gelembung emisi gas dasar laut. Pendeteksian gelembung emisi gas dasar laut ini dilakukan dengan menentukan ambang batas (treshold) intensitas pantulan gelombang akustik yang dipancarkan multibeam echosounder. Setiap obyek yang terdapat di kolom air memiliki nilai intensitas pantulan gelombang yang berbeda, dengan menentukan ambang batas intensitas gelombang kita dapat membedakan obyek yang terdapat di kolom air. Setelah gelembung emisi gas dasar laut atau obyek lain ditemukan, data kolom air tersebut divisualisasikan dalam bentuk gambar sehingga lebih mudah diamati. Hasil dari penelitian ini memperlihatkan bahwa data kolom air yang diambil menggunakan multibeam echosounder dapat digunakan untuk mengidentifikasi obyek yang terdapat pada kolom air. Pada penelitian ini ditemukan 82 titik sumber gelembung emisi gas dasar laut yang tersebar di wilayah perairan Kepulauan Mentawai, Indonesia.
\end{abstract}

Kata Kunci-Multibeam Echosounder, Data Kolom Air, Gelembung Emisi Gas Dasar Laut, Pemetaan Kolom Air.

\section{PENDAHULUAN}

$\mathrm{P}$ EMETAAN kolom air adalah sebuah metode penginderaan jauh menggunakan gelombang akustik yang digunakan untuk mengamati aspek lingkungan laut yang berada diantara permukaan laut dan dasar laut. Contoh aspek lingkungan laut yang dapat diamati seperti gelembung gas, biota laut, dan proses yang terjadi di dalam laut [1]
Alat yang digunakan untuk melakukan pemetaan kolom air adalah multibeam echosounder.

Alat multibeam echosounder pada umumnya digunakan untuk memetakan permukaan dasar laut. Akan tetapi, multibeam echosounder juga dapat digunakan untuk memetakan obyek yang berada di kolom air. Melakukan pemetaan kolom air dapat meningkatkan pengetahuan kita mengenai lingkungan laut, termasuk distribusi sumber daya alam gas bumi yang ada di laut dan kehidupan makhluk hidup yang berhubungan dengan gelembung emisi gas di dasar laut.

Adanya gelembung emisi gas yang muncul dari dasar laut biasanya menandakan adanya sumber cadangan minyak dan gas bumi. Gelembung emisi gas yang biasanya ada pada daerah sumber minyak dan gas bumi ini biasanya keluar dari dasar perairan kemudian menghilang di kolom air, atau naik sampai ke permukaan laut dan masuk ke atmosfer. Gelembung emisi gas yang keluar dari dasar laut ini merupakan target survei akustik yang dapat diamati karena gelembung emisi gas akan merespon gelombang akustik yang dipancarkan oleh multibeam echosounder[2].

Gelembung emisi gas yang ada di kolom air akan merespon gelombang akustik dari multibeam echosounder karena gelembung ini memiliki impedansi akustik yang berbeda dengan air yang mengelilinginya. Gelombang akustik yang merambat di air akan memantulkan kembali atau meneruskan sinyalnya ketika mengenai obyek yang memiliki impedansi akustik yang berbeda dengan medium yang sebelumnya, oleh karena itu multibeam echosounder dapat digunakan untuk mengamati dan memetakan gelembung emisi gas yang terdapat di kolom air[3].

Secara garis besar, gelembung emisi gas yang muncul dari dasar laut merupakan hasil dari perpindahan gas secara vertikal yang berasal dari bawah permukaan bumi seperti akumulasi hidrokarbon atau reservoir. Karena alasan ini, adanya gelembung emisi gas merupakan penyebab adanya eksplorasi minyak atau gas bumi secara global. Banyak ladang minyak dan gas bumi di Amerika Utara, Eropa, Asia, dan Karibia ditemukan setelah terlihatnya gelembung emisi gas ini [4].

Mendeteksi keberadaan emisi gas dan memetakan lokasinya merupakan langkah penting dalam memahami proses geologi dan biologi yang terjadi di dasar laut dan kolom air. Selain itu 
adanya gelembung emisi gas merupakan tanda adanya sumber minyak atau gas bumi yang nantinya dapat di eksplorasi dan di eksploitasi untuk dimanfaatkan oleh orang banyak.

Pada penelitian ini, data kolom air dari multibeam echosounder akan diekstrak dan disajikan dalam bentuk citra kolom air untuk memperlihatkan gelembung emisi gas yang ada di kolom air sehingga dapat diketahui lokasi titik sumber gelembung emisi gas di dasar laut.

\section{II.METODOLOGI PENELITIAN}

\section{A. Lokasi Penelitian}

Lokasi penelitian berada di perairan Kepulauan Pagai dan Kepulauan Mentawai, Indonesia yang berada pada rentang koordinat $1^{\circ} 00^{\prime} 18^{\prime \prime} \mathrm{LS}-4^{\circ} 36^{\prime} 45,13^{\prime}$ LS dan $98^{\circ} 09^{\prime} 18^{\prime \prime}$ BT - $103^{\circ} 06^{\prime} 16,70^{\prime \prime}$ BT. Daerah penelitian dibagi menjadi 2 zona, yaitu Zona 1 dan Zona 2.

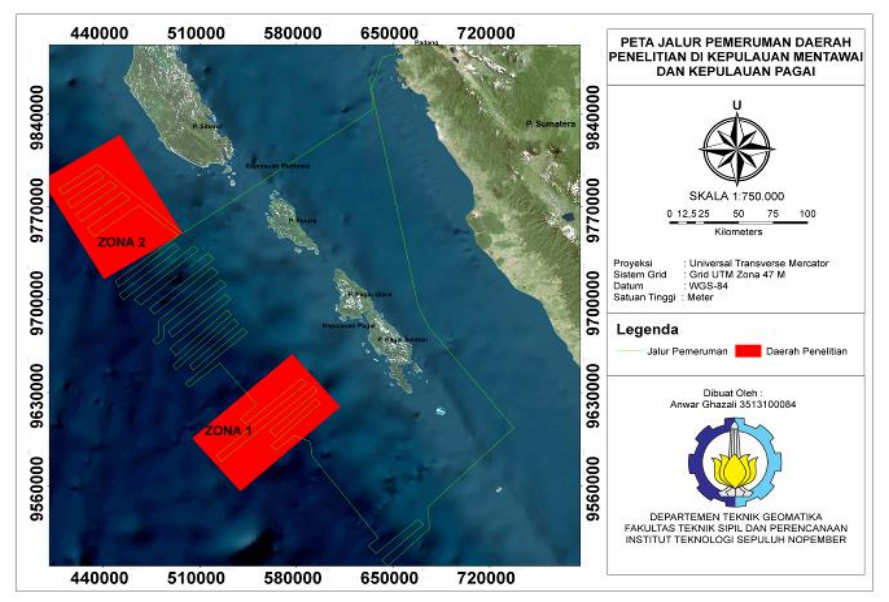

Gambar 1. Lokasi penelitian

Daerah ini dipilih sebagai area penelitian karena merupakan continental margin atau tepi benua. Continental margin merupakan daerah yang paling produktif dalam menghasilkan minyak dan gas bumi, sehingga kemungkinan ditemukannya gelembung emisi gas dasar laut cukup besar[5].

\section{B. Data dan Peralatan}

\section{1) Data}

Data yang digunakan dalam penelitian ini adalah data kolom air dan data batimetri yang diakuisisi menggunakan multibeam echosounder tipe Kongsberg EM710 dan EM302 yang terpasang pada kapal survei R/V Falkor. Kapal tersebut dioperasikan oleh UNOLS (University National Oceanographic Laboratory System) dan Schmidt Ocean Institute pada tanggal 23 Mei 2015 sampai dengan 22 Juni 2015. Total panjang jalur pemeruman pada survei ini adalah $4.826,5139 \mathrm{~km}$ dan terletak pada rentang koordinat $3^{\circ} 08^{\prime}$ $23,75^{\prime \prime}$ LU - 4 ${ }^{\circ} 36^{\prime} 45,13^{\prime}$ LS dan $91^{\circ} 39^{\prime} 36,9^{\prime \prime} \mathrm{BB}-103^{\circ} 06^{\prime}$ 16,70 ” BB[6][7].

Data ini merupakan data sekunder yang diunduh melalui situs resmi milik NOAA (National Oceanic and Atmospheric Administration). Data yang diunduh melalui situs resmi milik NOAA memiliki format (.wcd), untuk data kolom air, dan (.all) untuk data batimetri. Selanjutnya kedua data mentah ini akan diolah dan digabung menjadi satu dan memiliki format (.merged) untuk data batimetri dan format (.wc) untuk data kolom air.

\section{2) Peralatan}

Peralatan yang digunakan dalam penelitian ini dibagi menjadi dua, yaitu perangkat keras dan perangkat lunak. Perangkat keras yang digunakan pada penelitian ini adalah komputer dan laptop. Sedangkan perangkat lunak yang digunakan pada penelitian ini terdiri dari sistem operasi Ubuntu 14.04 dan Windows 7, perangkat lunak pengolah data DTM, perangkat lunak pembuat peta, dan perangkat lunak Swathed.

Swathed merupakan sebuah perangkat lunak yang dijalankan di sistem operasi Ubuntu. Swathed merupakan perangkat lunak non-komersil yang berfungsi untuk mengolah data batimetri dan kolom air yang dibuat oleh John E Hughes Clarke dari University of New Hampshire, US.

\section{Metode Pengolahan Data}

Dalam penelitian ini, ada beberapa tahapan yang perlu dilakukan untuk menganalisis gelembung emisi gas dasar laut. Tahap pertama adalah tahap ekstraksi data kolom air dan batimetri. Data awal yang didapatkan adalah data mentah dengan format (.all) untuk data batimetri dan (.wcd) untuk data kolom air. Pada tahap ekstraksi ini dilakukan proses unravel. Proses unravel adalah proses pengolahan data mentah dari multibeam echosounder agar selanjutnya dapat diolah menggunakan perangkat lunak Swathed. Data mentah yang memiliki format (.all) dan (.wcd) akan diolah dan digabung sehingga memiliki format baru, yaitu format (.merged) untuk data batimetri dan format (.wc) untuk data kolom air. Selanjutnya data tersebut dapat diolah menggunakan Swathed.

Tahap kedua adalah tahap pengolahan data kolom air. Pada tahap ini obyek yang ada di kolom air akan diidentifikasi untuk menemukan gelembung emisi gas dasar laut. Langkah pertama adalah dengan menentukan area pencarian di kolom air. Penentuan area pada kolom air ini berdasarkan beam, sample, swath, dan sektor. Hal ini dilakukan untuk mempersempit area pencarian sehingga mengurangi waktu pengolahan data. Jika area tidak ditentukan, maka seluruh data akan dijadikan sebagai area pencarian. Langkah kedua adalah menentukan nilai threshold. Threshold adalah batas dari sebuah nilai. Nilai yang digunakan dalam penelitian ini adalah nilai intensitas pantulan gelombang akustik. Penentuan nilai threshold ini dilakukan untuk menyeleksi obyek yang ada di kolom air. Obyek yang terdeteksi setelah penentuan nilai threshold adalah obyek yang memiliki nilai intensitas pantulan gelombang akustik yang lebih tinggi dari threshold, sehingga obyek yang memiliki nilai intensitas dibawah nilai threshold tidak akan terdeteksi.

Tahap ketiga adalah tahap interpretasi dan analisis data kolom air. Langkah pertama pada tahap ini adalah mencari LIM. LIM adalah intensitas gelombang akustik yang memiliki nilai paling tinggi dalam sebuah daerah pencarian di dalam data kolom air[6]. Pencarian LIM ini bertujuan untuk memastikan obyek yang ada pada citra kolom air bukan merupakan noise. Langkah kedua adalah memeriksa beam pattern. Beam pattern adalah pola gelombang akustik yang 
diterima oleh receiver pada multibeam echosounder. Pada tahap ini kita perlu menyesuaikan beam pattern yang terdapat pada obyek dengan replika beam pattern yang dianggap ideal pada program Swathed. Tujuan dari memeriksa beam pattern ini sama dengan mencari LIM, yaitu untuk memastikan obyek yang ada pada citra kolom air bukan merupakan noise. Setelah menemukan gelembung emisi gas dasar laut di kolom air, langkah selanjutnya adalah menganalisis gelembung tersebut. Dari data kolom air yang telah di interpretasi, kita dapat menganalisis posisi, titik kedalaman sumber gelembung, dan tinggi dari gelembung yang keluar dari dasar laut.

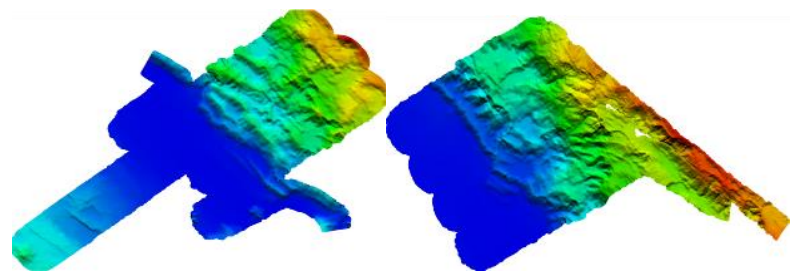

Gambar 2. DTM (Digital Terrain Model) Permukaan Dasar Laut Area Penelitian

Tahap keempat adalah pengolahan data batimetri. Pada tahap ini dilakukan gridding dan cleaning pada data batimetri dari multibeam echosounder. Spike dan noise yang ada pada data batimetri harus dihilangkan untuk menghasilkan DTM (Digital Terrain Model) permukaan dasar laut yang baik.

Tahap kelima adalah plotting sumber gelembung emisi gas dasar laut. Setelah didapatkannya DTM dari pengolahan batimetri dan koordinat sumber gelembung emisi gas dasar laut dari pengolahan data kolom air, langkah selanjutnya adalah melakukan plotting untuk meletakan titik sumber gelembung emisi gas dasar laut di peta untuk memberikan informasi spasial dari sumber gelembung tersebut. Hasil dari tahap ini adalah sebuah peta yang menampilkan persebaran titik lokasi sumber gelembung emisi gas dasar laut.

\section{HASIL DAN ANALISIS}

\section{A. Ekstraksi Data Kolom Air}

Data batimetri (.all) dan data kolom air (.wcd) perlu diolah terlebih dahulu sebelum dapat diolah menggunakan Swathed. Proses pengolahan data ini disebut unraveling. Data batimetri dan kolom air yang berasal dari multibeam echosounder perlu digabung kedalam satu folder. Beri nama folder tempat menyimpat data batimetri dan data kolom air tersebut dengan nama "raw".

Unravel ini adalah sebuah script yang digunakan untuk mengekstrak data batimetri dan data kolom air tersebut. Script ini akan membuat tiga folder tambahan tempat dimana hasil ekstraksi data batimetri dan data kolom air itu disimpan, ketiga folder tersebut adalah merged, ss, dan decnav. Data batimetri dengan format (.merged) dan data kolom air dengan format (.wc) yang akan digunakan selanjutnya berada di dalam folder merged. Selanjutnya data dengan format (.merged) dan (.wc) tersebut dapat diolah menggunakan Swathed.

\section{B. Visualisasi Data Kolom Air}

Setelah melakukan unravel, kita dapat melihat data batimetri (.merged) dan data kolom air (.wc) dengan cara mengetik perintah pada terminal yang terdapat di Ubuntu. Dengan cara mengetik "Swathed" pada terminal berarti kita bermaksud menjalankan program tersebut, diikuti dengan lokasi tempat data batimetri dan data kolom air disimpan "merged/JD162/0063 ...merged".

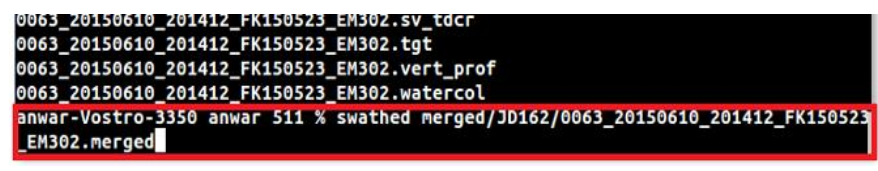

Gambar 3. Perintah Untuk Membukan Data Batimetri Dan Data Kolom Air Pada Terminal Ubuntu.

Setelah memasukan perintah berikut maka akan muncul jendela kerja Swathed. Beberapa fungsi dari jendela kerja Swathed ini adalah untuk melihat data batimetri dan melakukan cleaning pada data batimetri. Untuk memunculkan visualisasi dari data kolom air, klik tombol "WC" yang terletak di barisan toolbar pada jendela kerja Swathed. Data kolom air selanjutnya dapat dilihat pada jendela Water Column Analysis Toolkit.

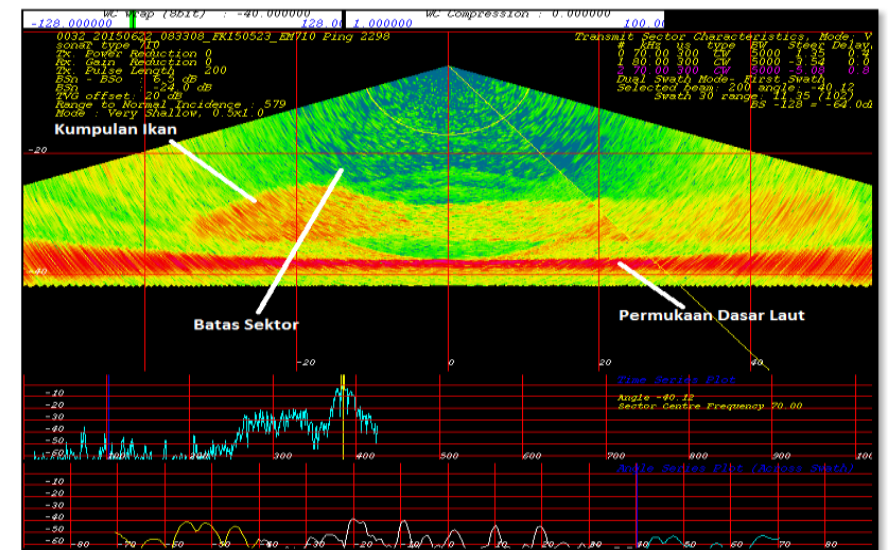

Gambar 4. Tampilan Across Track Pada Water Column Analysis Toolkit Yang Berfungsi Untuk Melihat Dan Menganalisis Data Kolom Air.

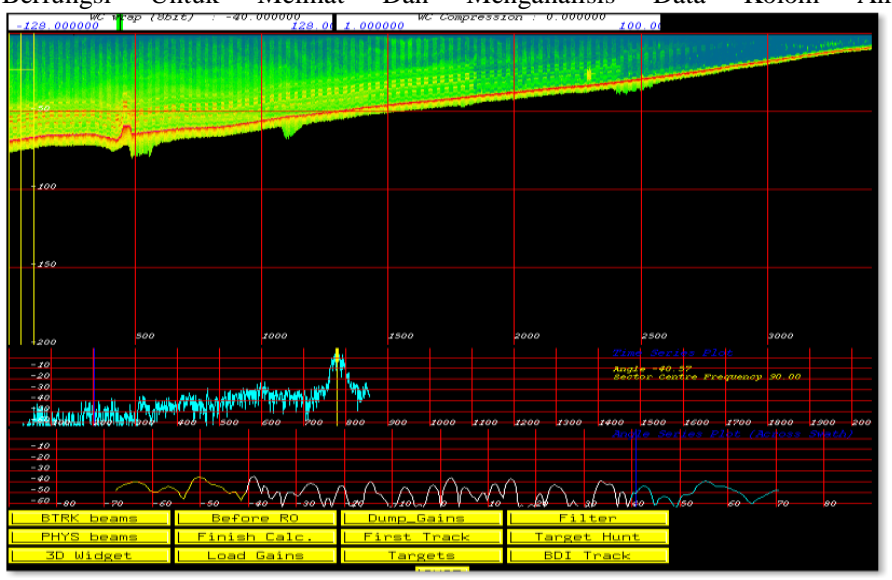

Gambar 5. Tampilan Along Track Pada Water Column Analysis Toolkit

Pada jendela Water Column Analysis Toolkit ini kita dapat mengamati obyek yang terdapat dikolom air serta menganalisis obyek tersebut dengan memperhatikan beam pattern dan intensitas pantulan gelombang akustik. 


\section{Interpretasi dan Analisis Data Kolom Air}

Beberapa obyek terlihat di dalam data kolom air, salah satu obyek tersebut adalah gelembung gas. Setiap gelembung gas yang terdeteksi memiliki nilai intensitas pantulan gelombang akustik diatas nilai threshold yang ditentukan. Nilai threshold yang ditentukan sebesar $0 \mathrm{~dB}$. Pada Gambar 6 terlihat gelembung gas yang terdeteksi ditandai dengan titik-titik berwarna biru. Titik-titik tersebut menandakan obyek tersebut memiliki intensitas pantulan gelombang akustik diatas nilai threshold yang telah ditentukan.

Pada Gambar 6 juga terlihat sumber gelembung gas (gas chimney) yang ada pada dasar perairan. Pada sumber gelembung gas tersembut terlihat memiliki intensitas pantulan gelombang akustik yang tinggi. Hal ini menandakan adanya perpindahan gas secara vertikal dari dalam dasar perairan ke permukaan dasar perairan. Adanya sumber gelembung gas dan gelembung gas di kolom air merupakan indikator adanya sumber gas yang aktif di dasar perairan tersebut[7].
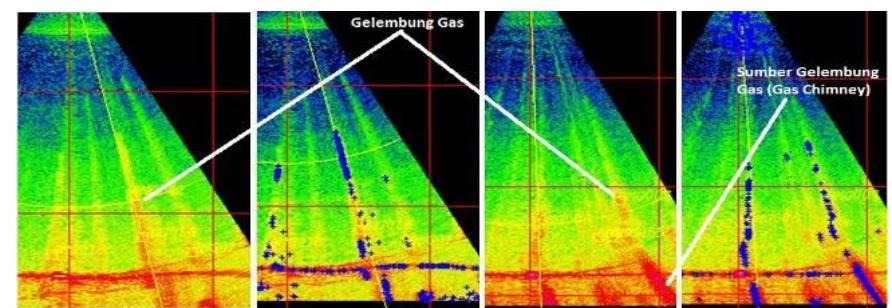

Gambar 6. Gelembung Gas Yang Terdeteksi Pada Tampilan Across Track View

Setelah obyek yang merupakan gelembung gas tersebut ditemukan, kita perlu mencari LIM pada obyek tersebut dan memeriksa beam pattern pada obyek tersebut untuk memastikan obyek tersebut bukan noise. Pada Gambar 8 dapat dilihat gelembung gas tersebut menunjukan adanya LIM dan memiliki beam pattern yang diharapkan. Adanya LIM ditandai dengan adanya spike tajam yang dapat dilihat pada ketiga grafik di Gambar 8. Spike tajam tersebut menandapat adanya perubahan nilai intensitas gelombang akustik yang signifikan pada obyek tersebut.

Time Series Plot adalah plot intensitas pantulan gelombang akustik terhadap sample, dari atas perairan hingga dasar perairan. Swath Series Plot adalah plot intensitas pantulan gelombang akustik terhadap swath. Sedangkan Angle Series Plot adalah plot instensitas pantulan gelombang terhadap sudut dari beam yang dipancarkan tranduser multibeam echosounder.
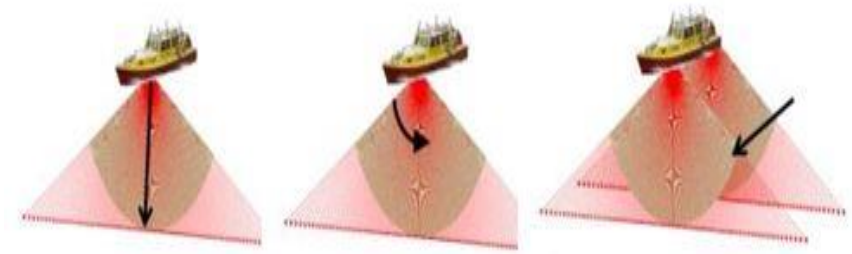

Gambar 7. Arah Plot Time Series Plot (Kiri), Angle Series Plot Across Swath (Tengah), Dan Swath Series Plot (Kanan) [8].

Pada grafik Time Series Plot, grafik pertama, memperlihatkan adanya LIM yang ditandai dengan meningkatnya nilai intensitas pantulan gelombang akustik.
Pada grafik pertama tidak terlihat signifikan dikarena obyek tersebut sejajar dengan kursor pada Swathed sehingga perubahan nilai intensitasnya terlihat seperti bukit, bukan spike.

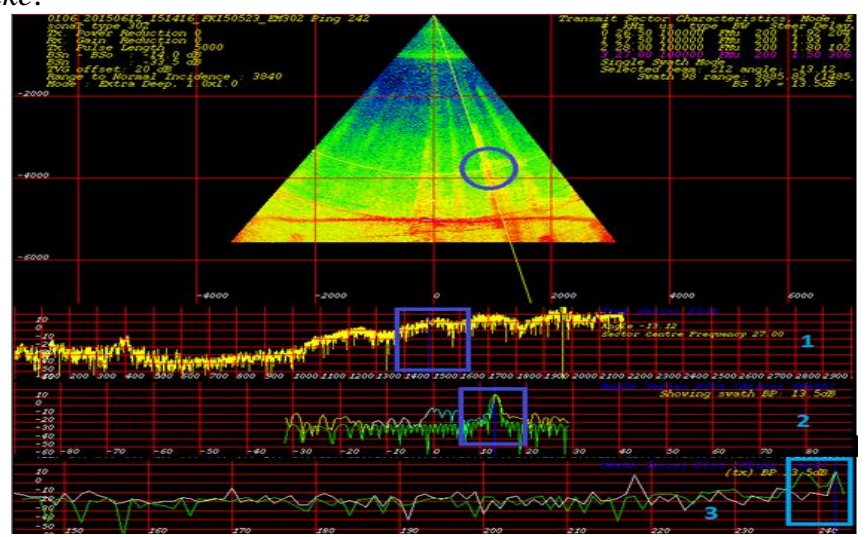

Gambar 8. Grafik Time Series Plot (1), Angle Series Plot (2), Dan Swath Series Plot Yang Menunjukan Adanya LIM Dan Kesesuaian Beam Pattern Pada Data Kolom Air

Pada grafik Angle Series Plot, grafik kedua, memperlihatkan adanya LIM ditandai dengan perubahan yang signifikan pada nilai intensitas pantulan gelombang akustik. Nilai intensitas yang dimiliki gelembung gas tersebut sebesar $13,5 \mathrm{~dB}$, sedangkan noise yang ada disekitarnya berada pada rentang $-30 \mathrm{~dB}$ sampai dengan $-20 \mathrm{~dB}$. Hal ini menandakan gelembung gas tersebut memiliki perbedaan intensitas gelombang akustik sebesar 30dB sampai dengan 40dB dengan noise yang ada di sekitarnya, sehingga bisa disimpulkan dari grafik kedua bahwa obyek tersebut bukan noise. Beam pattern yang terdapat pada grafik kedua juga memperlihatkan adanya kesesuaian dengan replika beam pattern yang dianggap sesuai. Replika beam pattern (garis hijau) hampir saling berhimpit dengan beam pattern yang ada pada kolom kedua, sehingga dapat disimpulkan bahwa LIM yang ditemukan pada grafik kedua bukan merupakan noise karena memiliki kesesuaian dengan replika beam pattern yang dianggap sesuai.

Pada grafik Swath Series Plot, grafik ketiga, memperlihatkan adanya LIM. Dapat dilihat nilai intensitas pantulan gelombang akustik yang terdapat pada swath dimana gelembung gas ditemukan memiliki perbedaan yang signifikan dengan nilai intensitas pantulan gelombang akustik yang ada pada swath sebelumnya. Perbedaan nilai intensitas pantulan gelombang akustik antara swath tempat gelembung gas berada dengan swath sebelunya sekitar 20dB. Dilihat dari beam pattern yang ada pada grafik ketiga, terdapat kesesuaian antara beam pattern yang dimiliki obyek dengan replika beam pattern yang dianggap sesuai. Hal ini dapat dilihat saling berhimpitnya beam pattern yang dimiliki obyek dengan replika beam pattern yang dianggap sesuai.

Dari ketiga grafik intensitas pantulan gelombang diatas, dapat disimpulkan bahwa obyek yang terlihat di kolom air tersebut bukanlah sebuah noise, melainkan gelembung gas yang muncul dari dasar perairan. Dapat dilihat pada Gambar 8 tersebut, sumber gelembung gas berada pada kedalam sekitar 4965 meter dari permukaan laut dan memancarkan gelembung gas setinggi 2242 meter dari sumber gelembungnya. 
Terdapat 82 sumber gelembung emisi gas dasar laut di area penelitian. Titik-titik tersebut kemudian di plot dan disatukan dengan DTM yang telah diolah. Pada Gambar 9 dapat dilihat persebaran lokasi sumber gelembung emisi gas dasar laut di perairan Kepulauan Mentawai terpusat di beberapa area. Terdapat 6 area dimana titik sumber gelembung emisi gas dasar laut tersebut berkumpul.

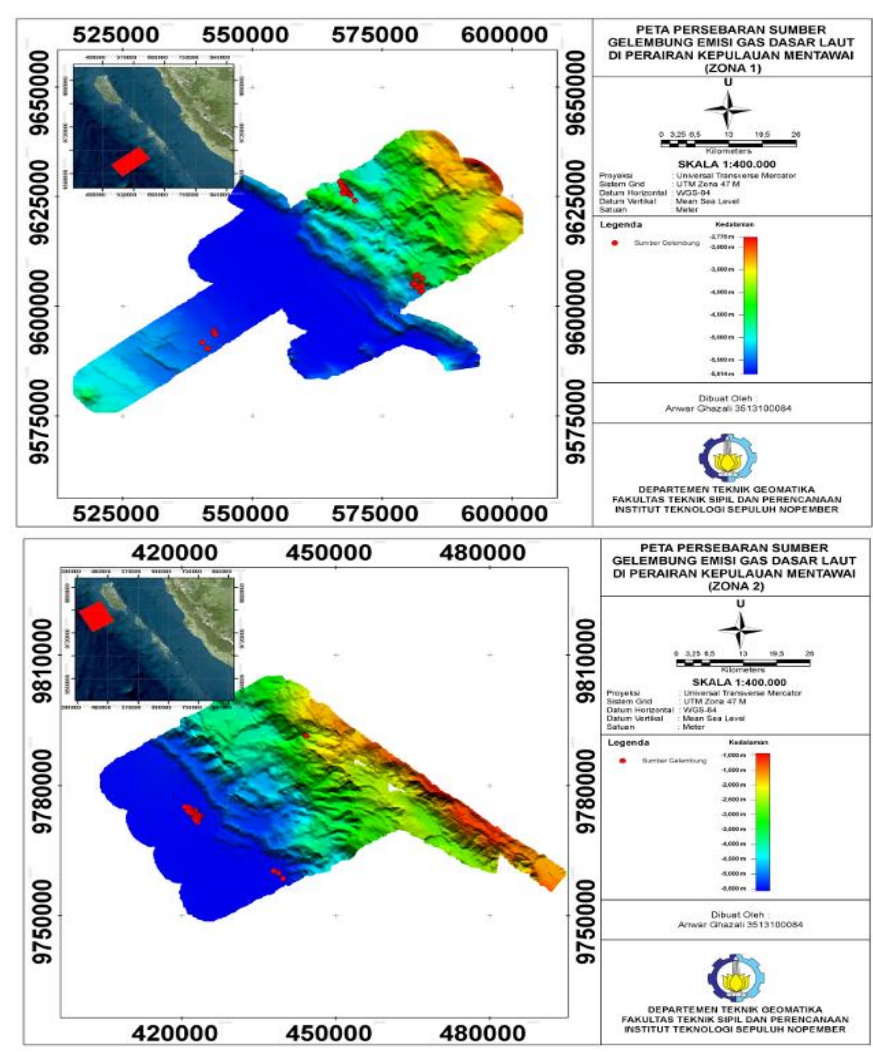

Gambar 9. Peta Persebaran Sumber Gelembung Emisi Gas Dasar Laut Di Perairan Kepulauan Mentawai

Pada Zona 1 terdapat 49 sumber gelembung emisi gas dasar laut yang terpusat di 3 area. Di Area 1 terdapat 13 sumber gelembung emisi gas dasar laut pada rentang kedalaman 4750$5150 \mathrm{~m}$. Terdapat 6 sumber gelembung di Area 2 pada rentang kedalaman 5550-5670 m. Sementara pada Area 3 terdapat 30 sumber gas pada rentang kedalaman 4940-5040 m.

Pada Zona 2 terdapat 33 sumber gelembung emisi gas dasar laut yang terpusat di 3 area. Di Area 4 terdapat 4 sumber gelembung pada rentang kedalaman 5540-5565 m. Terdapat 27 sumber gelembung pada Area 5 pada rentang kedalaman $5510-5600 \mathrm{~m}$. Sementara pada Area 6 terdapat 2 sumber gelembung gas pada rentang kedalaman 2860-2895 m.

\section{KESIMPULAN DAN SARAN}

Adapun hal-hal yang dapat disimpulkan dari penelitian ini adalah sebagai berikut :

1) Ekstraksi data kolom air dapat dilakukan dengan menggunakan program Swathed. Hasil ekstraksi dari data mentah multibeam echosounder berupa data kolom air (.wc) dan data batimetri (.merged).

2) Hasil visualisasi dari pengolahan data kolom air ini berupa citra kolom air yang memiliki nilai intensitas pantulan gelombang akustik. Dari perbedaan nilai intensitas pantulan gelombang akustik kita dapat mengamati objek yang ada di kolom air.

3) Hasil dari interpretasi dan analisis data kolom air ini adalah ditemukannya 82 titik sumber gelembung emisi gas dasar laut. Sumber gelembung gas ini terpusat di 6 area yang ada di wilayah perairan Kepulauan Mentawai, Indonesia. Informasi spasial dari sumber gelembung emisi gas dasar laut dapat dilihat di peta dan tabel pada lampiran.

Adapun saran yang dapat diberikan pada penelitian ini adalah sebagai berikut :

1. Ikan yang terdeteksi pada citra kolom air memiliki nilai intensitas gelombang akustik yang hampir sama dengan gelembung gas. Perbedaan antara gelembung gas dan ikan pada kolom air terlihat dari pola pergerakannya di kolom air. Untuk penelitian selanjutnya disarankan agar pola pergerakan gelembung gas diamati lebih lanjut lagi.

2. Pada penelitian selanjutnya dapat menggunakan data seismik dan/atau data sub bottom profiler untuk melihat volume dan lokasi gas yang ada di bawah permukaan dasar laut.

3. Pemilihan lokasi penelitian berperan penting dalam menemukan gelembung emisi gas dasar laut. Gelembung gas biasa ditemukan di sekitar pockmark, sand dome, atau gunung api di dalam laut. Analisis mengenai fitur dasar laut di sekitar titik sumber gelembung gas perlu diamati lebih lanjut untuk mengetahui hubungan antara fitur dasar laut dengan lokasi ditemukannya gelembung gas.

\section{UCAPAN TERIMA KASIH}

Penulis berterima kasih kepada NOAA (National Oceanic and Atmospheric Administration) yang telah menyediakan data multibeam echosounder dan disebarkan secara publik melalui www.ngdc.noaa.gov untuk digunakan pada penelitian ini.

\section{DAFTAR PUSTAKA}

[1] C. for C. and O. M. J. H. Center, "Water Column Mapping," 2016. [Online]. Available: http://ccom.unh.edu/sites/default/files/research_one_pagers/watercolumn-mapping.pdf.

[2] T. C. Weber et al., "Mapping Gas Seeps with the Deepwater Multibeam Echosounder on Okeanos Explorer," Oceanography, vol. 25, no. 1, Supplement, pp. 54-55, 2012.

[3] R. Sheriff and L. Geldart, Exploration Seismology, 2nd ed. Cambridge: Cambridge University Press, 1995.

[4] G. Etiope, Natural Gas Seepage. Cham: Springer International Publishing, 2015.

[5] N. R. C. (U.S.), Continental margins : geological and geophysical research needs and problems. National Academy of Sciences, 1979.

[6] C. Rubrio Marques and J. E. Hughes Clarke, "Automatic MidWater Target Tracking using Multibeam Water Column," Can. Hydrogr. Conf. 2012, no. May, pp. 1-15, 2012.

[7] Y. K. Jin, Y. G. Kim, B. Baranov, H. Shoji, and A. Obzhirov, "Distribution and expression of gas seeps in a gas hydrate province of the northeastern Sakhalin continental slope, Sea of Okhotsk," Mar. Pet. Geol., vol. 28, no. 10, pp. 1844-1855, 2011.

[8] C. Rubrio Videira Marques, "Automatic Mid-Water Target 
Tracking using Multibeam Water Column,” Department of Geodesy and Geomatics Engineering, University of New Brunswick, Fredericton, New Brunswick, Canada, 2012.

Tabel 1.

Informasi Gelembung Emisi Gas Dasar Laut Zona 1

\begin{tabular}{|c|c|c|c|c|c|}
\hline NO & NAMA OBJEK & LATITUDE & LONGITUDE & KEDALAMAN (m) & TINGGI GELEMBUNG GAS (m) \\
\hline 1 & GAS 1 & $-3,573401$ & 99,727801 & 5145,032715 & 1357,289 \\
\hline 2 & GAS 2 & \begin{tabular}{|l|}
$-3,578748$ \\
\end{tabular} & 99,733726 & 5133,371094 & 1175,78 \\
\hline \begin{tabular}{l|l}
3 \\
\end{tabular} & GAS 3 & $-3,576556$ & 99,73289 & 5128,018066 & 1453,507 \\
\hline 4 & GAS 4 & $-3,588924$ & 99,742203 & 5222,939941 & 1756,02 \\
\hline 5 & GAS 5 & $-3,571179$ & 99,729844 & 5037,411621 & 891,099 \\
\hline 6 & GAS 6 & $-3,579114$ & 99,735552 & 5180,023438 & 1297,92 \\
\hline 7 & GAS 7 & $-3,571237$ & 99,731859 & 5063,651367 & 1011,7 \\
\hline 8 & GAS 8 & $-3,585181$ & 99,744893 & 5131,461426 & 1098,382 \\
\hline \begin{tabular}{l|l}
9 \\
\end{tabular} & GAS 9 & $-3,575061$ & 99,744632 & 4872,333496 & 1688,493 \\
\hline 10 & GAS 10 & 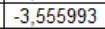 & 99,733405 & 4643,224121 & 1383,897 \\
\hline 11 & GAS 11 & $-3,561191$ & 99,742706 & 4700,294922 & 799,319 \\
\hline 12 & GAS 12 & $-3,552895$ & 99,736278 & 4586,682617 & 704,579 \\
\hline 13 & GAS 13 & $-3,560142$ & 99,745454 & 4755,046387 & 816,327 \\
\hline 14 & GAS 14 & $-3,668975$ & 99,382789 & 5666,949219 & 1575,57 \\
\hline 15 & GAS 15 & $-3,671614$ & 99,383492 & 5644,610352 & 2190,056 \\
\hline 16 & GAS 16 & $-3,677423$ & 99,385676 & 5688,387207 & 811,59 \\
\hline 17 & GAS 17 & $-3,706118$ & 99,372749 & 5558,015137 & 3177,832 \\
\hline 18 & GAS 18 & $-3,705277$ & 99,371618 & 5560,632324 & 2988,739 \\
\hline 19 & GAS 19 & $-3,692892$ & 99,36317 & 5580,896973 & 1262,321 \\
\hline 20 & GAS 20 & $-3,384445$ & 99,618541 & 5031,668457 & 690,555 \\
\hline 21 & GAS 21 & $-3,37308$ & 99,611058 & 5021,879883 & 793,808 \\
\hline 22 & GAS 22 & $-3,380675$ & 99,615716 & 5025,009277 & 345,354 \\
\hline 23 & GAS 23 & $-3,399794$ & 99,62791 & 5009,603027 & 988,508 \\
\hline 24 & GAS 24 & $-3,386114$ & 99,61896 & 5041,189453 & 1132,99 \\
\hline 25 & GAS 25 & $-3,370183$ & 99,608539 & 5026,26123 & 722,926 \\
\hline 26 & GAS 26 & $-3,377757$ & 99,613175 & 5006,157715 & 759,269 \\
\hline 27 & GAS 27 & $-3,383509$ & 99,61693 & 5004,074219 & 926,531 \\
\hline 28 & GAS 28 & $-3,388673$ & 99,620301 & 4966,163086 & 832,171 \\
\hline 29 & GAS 29 & $-3,361002$ & 99,602238 & 4945,527344 & 1488,912 \\
\hline 30 & GAS 30 & $-3,38305$ & 99,616293 & 5003,587891 & 3202,78 \\
\hline 31 & GAS 31 & $-3,373$ & 99,609855 & 4966,585449 & 1133,65 \\
\hline 32 & GAS 32 & $-3,381432$ & 99,614928 & 4985,880859 & 738,992 \\
\hline 33 & GAS 33 & $-3,386932$ & 99,618481 & 5004,78125 & 814,342 \\
\hline 34 & GAS 34 & $-3,37164$ & 99,608603 & 4986,71875 & 1040,886 \\
\hline 35 & GAS 35 & $-3,390401$ & 99,620172 & 4967,196777 & 682,676 \\
\hline 36 & GAS 36 & \begin{tabular}{|l|}
$-3,384486$ \\
\end{tabular} & $\begin{array}{l}99,61628 \\
\end{array}$ & 4967,781738 & 513,918 \\
\hline 37 & GAS 37 & $-3,36844$ & 99,605724 & 4967,637695 & 965,358 \\
\hline 38 & GAS 38 & $-3,372331$ & 99,608015 & 4947,900879 & 343,508 \\
\hline 39 & GAS 39 & $-3,367855$ & 99,604661 & 4946,875488 & 1810,132 \\
\hline 40 & GAS 40 & $-3,374672$ & 99,608816 & 4965,788574 & 2242,997 \\
\hline 41 & GAS 41 & $-3,385147$ & 99,615747 & 4985,871582 & 1755,048 \\
\hline 42 & GAS 42 & $-3,382765$ & 99,61318 & 4942,086426 & 2339,509 \\
\hline 43 & GAS 43 & $-3,369722$ & 99,604537 & 4943,772949 & 991,546 \\
\hline 44 & GAS 44 & $-3,381642$ & 99,612104 & 4998,706055 & 2031,359 \\
\hline 45 & GAS 45 & \begin{tabular}{|l|}
$-3,379508$ \\
\end{tabular} & 99,610399 & 4983,93457 & 1797,725 \\
\hline 46 & GAS 46 & $-3,379804$ & 99,61027 & 4980,222656 & 1009,758 \\
\hline 47 & GAS 47 & $-3,384728$ & 99,609011 & 4962,690918 & 1539,38 \\
\hline 48 & GAS 48 & $-3,382975$ & 99,60649 & 5015,65918 & 1118,149 \\
\hline 49 & GAS 49 & $-3,386276$ & 99,607799 & 4980,699219 & 864,326 \\
\hline
\end{tabular}

